\title{
A visão dos gestores e associados sobre a intervenção extensionista da unidade de cooperativismo da EMATER/RS- Ascar na gestão de uma cooperativa de crédito
}

\author{
Managers and associates' view on the extensionist intervention of \\ EMATER/RS-Ascar's cooperative unit in managing a credit cooperative
}

\author{
Bernardete Pilatti' , Rejane Inês Kieling" \\ 'Faculdade de Tecnologia do Cooperativismo - ESCOOP. bernapilatti@gmail.com \\ "Faculdade de Tecnologia do Cooperativismo - ESCOOP. rejanekieling@hotmail.com
}

\begin{abstract}
RESUMO
O presente trabalho apresenta a percepção dos gestores e associados da cooperativa de crédito Cresal sobre o trabalho realizado pela Unidade de Cooperativismo da Emater/RS-Ascar (UCP) junto à gestão dessa cooperativa. Utilizando-se o estudo de caso como recurso metodológico, foram apresentadas as características da cooperativa estudada e as ações realizadas pela Cresal em conjunto com a UCP no âmbito da estrutura organizacional e da gestão. Considerando-se as transformações desencadeadas a partir da intervenção da UCP na Cresal, o estudo procurou identificar e compreender a percepção dos gestores e associados sobre o processo em questão. Foram aplicados dois questionários e os resultados mostram que eles perceberam de forma positiva o trabalho da UCP. Os resultados apontam também que os que estiveram mais próximos dessa intervenção têm uma visão mais consonante com as ações realizadas do que aqueles que estiveram mais distantes do processo.
\end{abstract}

Palavras-chave: planejamento, extensão cooperativa, estrutura organizacional.

\section{ABSTRACT}

This study presents the perception of managers and associates from Credit Cooperative Cresal about the work carried out by Emater/RS-Ascar's Cooperative Unit. Using the case study as a methodological resource, we presented the characteristics of the cooperative investigated as well as the decisions they made along with Cooperative Unit in relation to their organizational structure and management. Considering the transformations triggered from the intervention of the Cooperative Unit at Cresal, the study sought to identify and understand the perception of managers and associates about the participation of the Cooperative Unit. Two questionnaires were applied and the results show that they 
perceived positively the work of the Cooperative Unit. The results, also, indicate that those who were closer to this intervention have more consonant view about the actions performed than those who were further away from the process.

Keywords: planning, cooperative extension, organizational structure.

\section{INTRODUÇÃO}

A preocupação com a gestão, associada à capacitação de gestores, é uma busca constante da grande maioria dos administradores de cooperativas, visto que esse tema está, muitas vezes, descrito dentro do planejamento dessas cooperativas. $\mathrm{Na}$ Cresal , Cooperativa de Economia e Crédito Mútuo dos Servidores da Ascar-Emater/RS, não é diferente. Desde que foi criada, passou por diversas mudanças importantes para se adequar às normas do cooperativismo de crédito como também proporcionar um melhor atendimento ao cooperado. Nos últimos anos foram feitas algumas ações mais voltadas ao planejamento, especialmente entre 2014 e 2016. Talvez a mais importante destas ações tenha ocorrido em 2016, ano que a cooperativa estudada assinou um Termo de Adesão ao PEC - Plano de Extensão Cooperativa, da SDR Secretaria do Desenvolvimento Rural, Pesca e Cooperativismo e cuja execução é feita pelas Unidades de Cooperativismo - UCP da Emater/RS-Ascar. Esse PEC visa diversas ações de melhoria na gestão, entre elas, capacitação e planejamento. Com a assinatura, a Cresal passou a ser atendida pela UCP de Porto Alegre e juntas desenvolveram diversas ações. $O$ trabalho em conjunto e as ações desenvolvidas promoveram mudanças na forma de pensar e atuar pelos gestores da cooperativa.

Diante desses fatos, percebeu-se a necessidade de avaliar as ações realizadas a partir da visão dos gestores e associados sobre a intervenção extensionista na gestão de uma cooperativa de crédito. Procurou-se saber então, como os gestores e associados da Cresal perceberam a intervenção da UCP que ocorreu no início de 2016 a meados de 2017, na gestão da Cresal. 
O termo "intervenção" nesse estudo se refere ao momento em que a Unidade de Cooperativismo passou a atuar junto à Cresal. Entende-se como tal por todo um contexto, em que, primeiramente é feito um diagnóstico da cooperativa e assinado o termo de adesão e, a partir disso, receber essa assistência nas ações de gestão. É como um marco que define essa interação.

Com o objetivo de analisar a visão dos gestores e associados sobre a intervenção da Unidade de Cooperativismo na estruturação da Cresal, foi feita uma pesquisa exploratória utilizando o método de Survey com a aplicação de dois questionários, e análise qualitativa dos resultados.

O primeiro questionário foi respondido pela equipe da Unidade de Cooperativismo de Porto Alegre e o Coordenador do Programa de Cooperativismo na Emater/RS-Ascar. Tal questionário visou atender ao primeiro objetivo específico: Identificar as ações realizadas pela Unidade de Cooperativismo - UCP junto à gestão da Cresal. Para tanto, foram elaboradas doze questões, cujas respostas trouxeram as ações realizadas junto à gestão da Cresal.

O segundo questionário, foi aplicado junto aos gestores da Cresal, compreendidos como a Diretoria, os conselheiros fiscais e administrativos, colaboradores e trabalhadores da área contábil da cooperativa, bem como os Representantes da Cresal do interior. Os resultados desse questionário visaram atender ao segundo, ao terceiro e ao quarto objetivos específicos, a saber: Apontar as maiores dificuldades encontradas pelos gestores e associados na gestão da Cresal antes da Intervenção da Unidade de Cooperativismo - UCP; Verificar se os participantes da pesquisa perceberam a intervenção da Unidade de Cooperativismo UCP na estruturação da Cresal e; Conferir os pontos positivos e negativos da intervenção da Unidade de Cooperativismo - UCP na Cresal pela visão dos seus gestores e associados. O segundo e o quarto, também estavam inseridos no 
questionário aplicado à equipe da UCP, cujos resultados puderam ser comparados à visão dos gestores sobre o trabalho executado.

O resultado apontou certa diferença na percepção da equipe da UCP sobre as dificuldades encontradas, com a percepção dos gestores sobre essas dificuldades. Teve também uma diferença de percepção entre os participantes do grupo dos gestores e associados da Cresal sobre o trabalho desenvolvido a partir da intervenção da UCP na Cooperativa. O grupo de gestores que esteve mais próximo e participou dessa intervenção percebeu muito mais ações realizadas e seus resultados, do que o grupo de associados, Representantes da Cresal, que não participou ativamente do trabalho desenvolvido. Dentre os pontos que se destacaram em consonância entre os grupos, foi a comunicação e a divulgação da cooperativa, e a educação cooperativa através do curso EAD que ocorreu em 2016 e 2018.

Esse trabalho apresenta uma revisão bibliográfica sobre o papel dos extensionistas nas cooperativas, que buscam minimizar os problemas enfrentados pelos agricultores familiares; a criação de normativos para atender as cooperativas e a estruturação da Emater/RS-Ascar para fazer esse atendimento e uma abordagem à Educação Cooperativa e Capacitação com ênfase à comunicação.

\section{REFERENCIAL TEÓRICO}

Antes de adentra-se nos resultados do caso estudado, faz-se necessário apresentar as bases teóricas que sustentam as análises e considerações do presente estudo. A revisão teórica está dividida em três direcionamentos: $1^{\circ}$. O papel do extensionista nas cooperativas; $2^{\circ}$. A Lei $13.839 / 2011$ e o Decreto 49.333/2012 que regulamenta os normativos da base legal e a criação das Unidades de Cooperativa pela Emater/RS-Ascar; $3^{\circ}$. Referências sobre Educação e Capacitação Cooperativa. 
2.1 O papel do extensionista nas cooperativas

Um dos principais problemas enfrentados pelos agricultores familiares, segundo Melo (2013) é o acesso ao mercado e a compreensão de seu funcionamento. Para este autor, a maioria dos agricultores familiares tem conhecimento empírico suficiente para o trabalho básico inicial da produção, mas para um desempenho do empreendimento rural, há a dependência de muitas variáveis, como por exemplo: a dificuldade no acesso a comercialização e precificação dos produtos, um controle de produção eficiente com uma "escala" de produção que visa prevenir perdas e prejuízos, bem como o alto custo para aquisição de insumos.

Existem algumas formas de atenuar essas dificuldades no campo. Uma delas é valer-se dos serviços de assistência técnica e extensão rural prestado por instituições públicas ou privadas. O tema da Extensão Rural está em permanente discussão, tanto na academia quanto entre os formuladores de políticas públicas, e entre extensionistas. Segundo Peixoto (2008) diversos estudos, no Brasil e no exterior, apresentam enfoques históricos, modelos e sistemas, metodologia de ação, formas de organização e outros. No entanto, complementa o autor, aparentemente há uma carência de estudos sobre a regulação desta atividade.

O mesmo autor propõe que o termo extensão rural possa ser conceituado de três formas diferentes: como processo, como instituição e como política. Como processo, seria "o ato de estender, levar ou transmitir conhecimentos de sua fonte geradora ao receptor final, o público rural." (PEIXOTO, 2008, p. 7). Há de se considerar, ainda, que o termo extensão rural pode ser entendido como um processo educativo de sociabilidade e de conhecimentos de qualquer natureza, sejam conhecimentos técnicos ou não. Por ter um caráter educativo, normalmente esse serviço é realizado pelas instituições públicas, organizações não governamentais, e cooperativas. A extensão rural como instituição, refere-se às organizações estatais dos estados, prestadoras dos serviços de Assistência Técnica e Extensão Rural - Ater. É a entidade 
ou organização pública prestadora de serviços de Ater nos estados. E finalmente como política a extensão rural se refere às políticas públicas de extensão rural, traçadas pelos governos federal, estaduais ou municipais que podem ser executadas por organizações públicas e/ou privadas. Melo (2013) contribui e enriquece as interpretações de Peixoto (2008) ao afirmar que existe a possibilidade de, através do cooperativismo, a extensão rural levar ferramentas administrativas úteis aos produtores rurais familiares.

2.2 O Programa de Extensão Cooperativa e a criação das Unidades de Cooperativismo - UCPS

O Rio Grande do Sul caracteriza-se pela vocação ao cooperativismo, haja vista o grande número de pessoas envolvidas de alguma forma ao sistema cooperativo gaúcho. O Jornal do Comércio de 12 de julho de 2019 traz a manifestação de Virgílio Perius que diz que as cooperativas gaúchas alcançaram 2,9 milhões de pessoas, quando avaliados os números de associados, e 437 cooperativas. No entanto, muitas destas organizações enfrentam dificuldades de gestão, sobretudo as de menor porte.

Em 2011, num esforço integrado às ações do governo estadual gaúcho em benefício da agricultura familiar pela estruturação e valorização do cooperativismo, a Emater/RS-Ascar ${ }^{1}$ formou um grupo de 25 extensionistas para assessorar as cooperativas do estado. A organização inicialmente consistia em cinco núcleos no Estado do Rio Grande do Sul, distribuídos regionalmente, cujas equipes compunham profissionais das áreas de produção, comercialização, planejamento, contabilidade, administração e educação, e visava atender as cooperativas, especialmente na parte de gestão. Essa ação da Emater/RS-Ascar, inserida no programa estadual de fomento

\footnotetext{
${ }^{1}$ A Associação Sulina de Crédito Assistência Rural (Ascar) surgiu em 02 de junho de 1955 e tem como objetivo promover o desenvolvimento da agricultura e o bem-estar das populações do meio rural. Em 1977, a Ascar passou a atuar em conjunto com a Associação Riograndense de Empreendimentos de Assistência Técnica e Extensão Rural (Emater/RS), criada em 14 de março de 1977. Ambas as entidades são sociedades civis de direito privado sem fins lucrativos que executam as atividades oficiais de Assistência Técnica e Extensão Rural no Rio Grande do Sul, cuja denominação oficial é Emater/RS-Ascar. Os extensionistas são vinculados à Ascar.
} 
ao cooperativismo da Secretaria do Desenvolvimento Rural, Pesca e Cooperativismo SDR, com a qual mantinha convênio, teve foco no trabalho de extensão com apoio à gestão e educação para as cooperativas.

Em 05 de dezembro de 2011, quando o Governo do Estado do Rio Grande do Sul criou a Lei n 13.839 que instituiu a Política Estadual de Fomento à Economia da Cooperação, a Emater já estava capacitada para atender essa demanda. Nessa Lei foram previstas normas que constituem vários programas de fomento à economia, dentre eles o Programa de Cooperativismo.

A partir da Lei $n^{\circ}$ 13.839, foi criado o Decreto 49.333 de 04 de julho de 2012, que instituiu o Programa de Extensão Cooperativa - PEC - RS o qual está no campo da "Política Estadual de Fomento à Economia da Cooperação e do Programa de Cooperativismo do Estado do Rio Grande do Sul" (RIO GRANDE DO SUL - RS, 2011, p. 01).

O artigo $5^{\circ}$ do Decreto 49.333/2012 traz como proposta do PEC - RS "introduzir melhorias técnico-gerenciais, produtivas e educacionais nas cooperativas com a finalidade de incrementar a competitividade, promover a interação, a cooperação entre associados e cooperativas, bem como apoiar a sua criação" (RIO GRANDE DO SUL, 2012, p. 02). Inicialmente, esse decreto visava atender somente às cooperativas agropecuárias, especialmente as da agricultura familiar, público prioritário da Emater/RS-Ascar e que representa um total de 85\% dos produtores gaúchos, contudo, a partir de 2015, passou a ser uma política de governo o atendimento a todos os ramos do cooperativismo. Nesse período a Emater/RS-Ascar já contava com mais duas Unidades de Cooperativismo - UCP. Uma delas na Região de Porto Alegre abrangendo a região metropolitana e a capital do Estado.

Com o objetivo de promover o desenvolvimento das cooperativas, o PEC-RS ficou sob a coordenação da Secretaria de Desenvolvimento Rural, Pesca e 
Cooperativismo - SDR e, pelo convênio com essa Secretaria, a Emater/RS-Ascar assumiu a execução do programa, através das Unidades de Cooperativismo UCPs.

As Unidades de Cooperativismo - UCPs foram criadas pela Emater/RS-Ascar em agosto de 2011 com o propósito de suportar essa demanda. As UCPs são constituídas por equipes multidisciplinares de extensionistas da Emater, capacitadas a atender as diferentes cooperativas do Estado do Rio Grande do Sul. Essas equipes são responsáveis por realizar as atividades de extensão junto às cooperativas que solicitam ajuda e aderem ao programa. Os termos contidos na PEC instituem os seguintes passos para realização em cada empreendimento: a) diagnóstico; b) plano de aprimoramento; c) projetos de implantação das recomendações do plano de aprimoramento para solucionar os problemas de gestão, produção, industrialização e/ou comercialização; d) assistência pelo período de 18 meses.

O Programa especifica que esse atendimento junto à gestão das cooperativas, ocorre de forma confidencial, tendo acesso aos dados da cooperativa atendida, às equipes das UCPs, coordenações do Programa pela Emater/RS e Departamento de Cooperativismo da SDR-RS. Para que esse trabalho ocorra, a cooperativa se compromete com: a) o fornecimento dos dados para a elaboração do diagnóstico e demais levantamentos de dados; b) acompanhar os trabalhos da equipe da UCP, colaborando nas visitas técnicas; c) compromisso com a execução nos termos acordados; e d) participação nas etapas de monitoramento e avaliação do processo.

Contudo, para que um processo se dê de forma clara e traga os resultados esperados, faz-se necessário, conforme advertem Freitas, Freitas e Pedra (2011), uma efetiva participação dos cooperados nos processos de reflexão e ação, em que o cooperado internaliza o sentimento de pertencimento e a condição de dono da cooperativa. Nesse sentido cabe à cooperativa oportunizar à participação social. Esse envolvimento deve ser estimulado pela própria cooperativa, uma vez que a motivação espontânea nem sempre acontece. 


\subsection{Educação e capacitação cooperativa}

Schneider, Hendges e Silva (2010) falam sobre a importância de conhecer antes de emitir opinião sobre qualquer assunto. O cooperativismo não é de conhecimento comum entre as pessoas, haja vista que muitas veem o cooperativismo como algo dissimulado, relacionado com envolvimento político. Segundo os autores, nem mesmo os próprios associados possuem condições de conceituar o que seria uma cooperativa, e que a educação para uma cooperação deveria ser de livre acesso às pessoas, visto que a maioria desconhece a natureza e as funções específicas das cooperativas nos diversos países.

O conjunto de técnicas e de ensinamentos dados às pessoas a fim de que estas desempenhem com maior eficiência e qualidade o seu trabalho, pode-se chamar de Formação e Capacitação Cooperativa. Segundo os autores, o conceito de capacitação deve ser entendido como a possibilidade de aperfeiçoamento das capacidades individuais das pessoas e não como um mero adestramento.

Para os autores supramencionados, a educação está mais ligada a valores, princípios e normas, enquanto a formação e capacitação estão relacionadas à profissionalização. Segundo os autores, a perspectiva de educação cooperativa que ele apresenta, está mais próxima da cooperativa enquanto "associação de pessoas", e a capacitação estão mais próximas à cooperativa enquanto "empresa".

É imprescindível, nos tempos atuais, as cooperativas adotarem uma política de comunicação que permita divulgar mais sua identidade, sua filosofia e suas ações nas várias e específicas funções junto aos seus cooperados e na sociedade em geral. Schmitz (2003) diz que a comunicação tem um papel fundamental nas organizações cooperativas, especialmente no que tange às diferentes relações entre seus vários públicos. As cooperativas têm princípios que servem de diretrizes para a prática dos 
valores cooperativos. Entre os princípios e valores, a autora chama a atenção à proposta democrática das cooperativas, fundamentada na participação, seja no campo político, no social ou no econômico. "O associado deve participar da vida da cooperativa considerando os vários aspectos que a caracterizam, pois, ao mesmo tempo que é dono da empresa, é também usuário dos serviços e instalações da mesma" (SCHMITZ, 2003, p. 199). Podemos entender com isso, que a cooperativa precisa propiciar essa participação. A comunicação é a ação que estabelece que o cooperado interaja na cooperativa, se apropriando das informações que permeiam o cooperativismo e principalmente as informações sobre a organização a que faz parte. Essa participação pode ocorrer "por meio da integração da comunicação e da educação dos conceitos, [...] pode-se implementar um processo de educação nas cooperativas, contribuindo para o exercício da cidadania e para a valorização dos seus diversos públicos." (SCHMITZ, 2003, p. 199).

Entretanto, a ação de comunicar e difundir as informações não é o bastante. É fundamental que a informação seja repassada de forma a ser compreendida na sua integridade. Segundo Seger, Eckhardt e Gessi (2016), estamos num universo em que existem muitos problemas de distorções das mensagens enviadas. Dentro da organização não é diferente. Segundo os autores, as informações não chegam ao receptor de maneira clara, ocorrendo uma perda da eficiência no correto andamento das atividades e principalmente a perda da lealdade dos colaboradores e consumidores. Há uma necessidade eminente de os gestores tomarem consciência da importância da comunicação e de que forma ela está sendo conduzida. "Somente quando as organizações perceberem que a comunicação eficaz é de suma importância para o andamento correto das atividades poderá atingir excelência dos produtos e serviços." (SEGER, ECKHARDT e GESSI, 2016. p. 01). 


\section{PROCEDIMENTO METODOLÓGICO}

A presente pesquisa buscou analisar a visão dos gestores e associados sobre a intervenção da Unidade de Cooperativismo - UCP na estruturação da Cresal. De acordo com Gil (2009) esta pesquisa pode ser classificada como exploratória, uma vez que o problema levantado não é conhecido e se tornará mais explícito a partir dos resultados analisados. Já com relação a sua abordagem essa pesquisa pode ser classificada como qualitativa por abranger aspectos mais específicos relacionados ao comportamento e compreensão das relações sociais.

Para a coleta de dados foi escolhido o método de estudo de caso tendo como público alvo a Cooperativa de Economia e Crédito Mútuo dos Servidores da Ascar/Emater/RS - Cresal. Para melhor entendimento do objeto deste estudo, considera-se importante apresentar breve histórico da cooperativa estudada.

Observa-se que a pesquisadora trabalha na Emater/RS-Ascar, é associada da Cresal e participou da intervenção da UCP como gestora da Cresal.

\subsection{Estudo do caso Cresal}

Fundada em 1983, a Cresal foi organizada de forma a dar suporte financeiro aos empregados da Ascar a fim de que estes pudessem obter empréstimos com taxas menores, prazos adequados, melhores condições de acesso, além de melhores juros na aplicação das economias pessoais. Outro motivo que incentivou os fundadores a criarem a cooperativa na época, foi a possibilidade de aquisição de experiência e conhecimento teórico-prático que, participando na vida de uma cooperativa como associados, qualificaria o trabalho de extensão junto ao público rural. É importante destacar que o público associado são trabalhadores da Emater/RS-Ascar que tem como atividade fim a extensão rural, e sua abrangência é o estado do Rio Grande do Sul (site da Cresal). 
Nesses mais de 35 anos, a Cresal passou por vários processos de atualização além de encontrar formas de se manter no mercado, como a ampliação do portfólio de produtos e serviços, que se refere a Aplicações e Empréstimo, além dos serviços de planos de saúde Unimed e Uniodonto e seguros Proseg (site da Cresal).

Em 2016, buscando qualificar a gestão e a organização estrutural da cooperativa, a diretoria com a anuência do Conselho de Administração aderiu ao Programa de Extensão Cooperativa - PEC, assinando um Termo de Adesão. A partir dessa data a Cresal passou a receber o atendimento da Unidade de Cooperativismo UCP de Porto Alegre, que na ocasião, contava com uma Socióloga, uma Administradora, um Economista e um Engenheiro Agrônomo.

A iniciativa da Cresal em aderir ao PEC, corroborou o Plano de Ação dela, elaborado em 2014 pelos gestores e conselheiros da Cresal mais as colaboradoras e a contadora da cooperativa. Esse Plano de Ação havia sido construído com o objetivo de facilitar e coordenar os trabalhos desenvolvidos pela Cresal que precisava de uma organização mais participativa para alcançar o público cooperativado. O Plano em questão teve como facilitador o Professor Alberto Bracagioli, que nesse período ministrava aulas na Faculdade de Tecnologia do Cooperativismo - Escoop.

Esse Plano visava organizar a cooperativa estruturalmente e estrategicamente pensando nos mecanismos para a divulgação da cooperativa e, ao mesmo tempo, oportunizar aos participantes da construção do planejamento em questão, o conhecimento das informações e processos de gestão com um viés educativo. Esse trabalho ocorreu durante três noites, com intervalo de uma semana entre um encontro e outro, e que implicou em um período maior de envolvimento dos participantes no assunto. 
O plano, na ocasião, foi de grande importância, especialmente por ter havido um envolvimento mais ativo dos membros dos conselhos nos assuntos da Cresal. Foi a partir dele que a Cresal passou a contar com Representantes da $\mathrm{Cresal}^{2}$, por região administrativa da Emater/RS-Ascar, escolhidos entre os cooperados pertencentes àquela Região Administrativa ${ }^{3}$. A criação do agente Representante da Cresal visou alcançar os cooperados e cooperados em potencial em todo o estado do Rio Grande do Sul, repassando informações, divulgando a Cresal e seus produtos, falando sobre o cooperativismo, sendo, portanto, o elo de comunicação entre associado e a organização cooperativa Cresal na sua região. Uma extensão da gestão da Cresal no interior, vindo ao encontro das teorias de Schmitz (2003) que dizem que o associado precisa participar da vida da organização cooperativa.

A aplicação das ações, no entanto, revelou a falta de estrutura física e de pessoal da Cresal, além da dificuldade de compreensão das tarefas a serem executadas. As ações não estavam sendo realizadas nas datas previstas, nem com o mesmo empenho que o planejado. O fato de os membros da Diretoria não terem liberação da empregadora (Ascar) para atuar na cooperativa, dificultava bastante. Mesmo tendo um Plano de Ação para seguir, o que dava agilidade e segurança nas tomadas de decisão, a falta de tempo e estrutura organizacional acabava interferindo no processo, implicando, às vezes, na modificação da ação ou simplesmente no seu abandono. Porém, essa fragilidade toda, não impediu que no ano seguinte, fosse feita uma avaliação e revisão do planejamento. Foi nessa ocasião que a Cresal tomou conhecimento do Programa de Extensão Cooperativa (PEC-RS) e da Unidade de Cooperativismo disponibilizada pela Emater/RS-Ascar.

\footnotetext{
${ }^{2}$ Os Representantes da Cresal são cooperados do interior do Estado, distribuídos de acordo com a divisão das regiões administrativas da Emater/RS-Ascar e que fazem um trabalho voluntário de fomentar as ações de divulgação da cooperativa, seguindo os princípios do cooperativismo e normas e ações definidas pela cooperativa. Esse Representante visa ser um elo de comunicação entre a cooperativa e o cooperado na sua região de atuação e são escolhidos entre os cooperados pertencentes a Região Administrativa correspondente. O período da ação é o mesmo da diretoria da Cresal, 3 anos, podendo ser reconduzido

${ }^{3}$ As Regiões Administrativas da Emater/RS-Ascar são as divisões da área territorial do Rio Grande do Sul comportando um número de municípios e que visam facilitar a integração institucional e o conjunto do trabalho. A Emater/RS-Ascar têm doze regionais.
} 
Assim, em janeiro de 2016, por intermédio do coordenador do Programa de Cooperativismo na Emater/RS-Ascar, a Cresal procurou a UCP de Porto Alegre e assinou o Termo de Adesão passando a contar com a expertise da equipe de extensionistas dessa UCP. Com o aceite deste termo, a cooperativa iniciou o trabalho com a Unidade de Cooperativismo de Porto Alegre. A UCP fez um diagnóstico inicial com a aplicação de um questionário que foi respondido por todos os conselheiros de administração e fiscal, mais colaboradora e contadora da cooperativa. Esse diagnóstico permitiu fazer um planejamento das ações da equipe da UCP junto à Cresal com distribuição de tarefas e prazos.

A Cresal desenvolveu diversas ações em conjunto com a equipe da UCP. Entre elas, destacam-se: a) a organização do I e II Encontro com capacitação dos representantes da Cresal realizado em abril de 2016/2017 - Encontro dos Representantes da Cresal e Formação com UCP; b) I e II encontro do cooperativismo na Emater realizado em junho de 2016 e 2017 em alusão ao Dia do Cooperativismo Encontro do Cooperativismo da Cresal e Emater/RS; c) a reorganização do planejamento estratégico com revisão das diretrizes estratégicas da Cresal: missão, visão e valores, em junho de 2016 e; d) a criação de um curso EAD de Educação Cooperativista da Cresal, sendo oferecido de forma gratuita tanto para os cooperados como para o público cooperado em potencial que são os trabalhadores da Emater/RS-Ascar. Essa última foi desenvolvida em parceria com a Emater/RS-Ascar, com o objetivo de trabalhar o cooperativismo para o público interno dessa instituição, que, apesar de desenvolver ações nessa área, nem todos os trabalhadores assimilam o cooperativismo na sua essência: contexto histórico, valores, princípios, símbolo, além de outros temas como o cooperativismo de crédito; participação, direitos e deveres dos associados; gestão cooperativista; gestão financeira; e a própria história da Cresal, assuntos que foram trabalhados neste curso. Essa atividade vem ao encontro da teoria de Schneider, Hendges e Silva (2010) que dizem que a educação cooperativa precisaria ser de livre acesso às pessoas, devido à falta de conhecimento da maioria sobre a sua natureza e função. 
Para que fosse desenvolvido o Curso EAD, as duas entidades entenderam ser necessário ter um documento que assegurasse essa parceria tendo em vista a prática de ações em conjunto. Por isso, em setembro do mesmo ano, 2016, a Emater/RSAscar e a Cresal, firmaram um Termo de Cooperação Técnica Interinstitucional com base no Programa de Extensão Cooperativa, visando o desenvolvimento de programas gerenciais, produtivos e educacionais entre cooperados, cooperativa e empregados. O Termo permitiu que a Cresal, junto com a equipe da UCP de Porto Alegre, bem como as demais Unidades de Cooperativismo da Emater, pudesse desenvolver um trabalho de extensão voltado para o público interno da Emater/RSAscar, objetivando a educação cooperativista entre os cooperados e demais empregados da Ascar. Essa parceria também oportunizava à UCP trabalhar o cooperativismo de crédito como forma de ganhar experiências neste ramo cooperativo. Com isso, ainda em 2016, foi realizado o primeiro Curso de Educação à

Distância - EAD de Educação Cooperativista da Cresal com destaque ao cooperativismo de crédito. Para aplicar o curso, em virtude de a Cresal não ter estrutura física e virtual de postagem, foi utilizada a Plataforma PAR - Programa de Aprendizagem em Rede, da Emater/RS-Ascar. Esse curso teve uma segunda edição em 2018.

Essas ações desenvolvidas em conjunto entre a Cresal e a UCP promoveram mudanças na forma de agir e pensar dos gestores e associados da cooperativa. Por esse motivo pensou-se em analisar a visão dos envolvidos nessa articulação sobre a intervenção da Unidade de Cooperativismo - UCP na Cresal.

\subsection{Instrumentos de coleta de dados}

A fim de concretizar essa pesquisa foi utilizado o método Survey com a aplicação de dois questionários. O primeiro, com 12 questões abertas e fechadas, foi respondido pela equipe da UCP envolvida na intervenção junto à Cresal durante o 
período de 2016 a meados de 2017, e ações pontuais em 2018. Já o segundo questionário, composto por 21 questões subdivididas em três tópicos: a) Identificação; b) Dificuldades da Cresal antes da Intervenção da Unidade de Cooperativismo - UCP; c) Unidade de Cooperativismo - UCP e a sua intervenção na Cresal foi respondido pelos gestores e associados da Cresal.

Para validar os questionários, foi feito um pré-teste, pesquisa exploratória, sendo estes enviados a uma integrante da equipe da UCP, que retornou resultado satisfatório.

\subsection{Público alvo da pesquisa}

O público que participou da pesquisa são trabalhadores da Emater/RS-Ascar, todos associados da Cresal, porém com papéis diferentes na função ou atuação. $O$ primeiro grupo, integrantes da Equipe da UCP de Porto Alegre - quatro pessoas - e o Coordenador das Unidades de Cooperativismo na Emater/RS-Ascar, são extensionistas que trabalham diretamente com cooperativas. Estes cinco participaram da pesquisa respondendo o questionário 1.

Já o segundo é formado por Conselheiros de Administração, Conselheiros Fiscais, Representantes da Cresal do interior do RS, pessoas que trabalham na Cresal na área administrativa e contábil e Diretoria, e que atuaram em conjunto com a UCP na estruturação da Cresal. Estes responderam o questionário 2. Desse segundo grupo, foi feita uma subdivisão para melhor compreensão das respostas recebidas, ficando assim distribuídos: pessoas que trabalharam diretamente e os mais próximos, ficaram classificados como Grupo 1, e os que estiveram mais distantes do processo, ficaram classificados como Grupo 2. 
Grupo 1 - 10 pessoas: Diretoria - 3 pessoas; Conselheiros de Administração e Fiscal e Ex-conselheira - 6 pessoas; Área contábil - 1 pessoa. Desses, quatro tem menos de três anos na gestão, período posterior ao estudado;

Grupo 2 - 15 pessoas: Associados do interior que atuaram como Representantes da Cresal no período estudado. É importante destacar que os Representantes da Cresal não atuam diretamente nas ações realizadas na cooperativa. Estes fazem parte de um grupo criado para facilitar a comunicação entre a diretoria e os associados. Por desempenharem esse papel, e por terem acesso à capacitação cooperativa, presumese que esses associados procuram se manter mais bem informados sobre as ações da cooperativa em comparação aos demais associados, o que cria um parâmetro para aplicar a pesquisa. Contudo, apesar de sua atuação como Representante, sua participação na cooperativa está mais para associado que para gestor.

É importante destacar também que a escolha desse grupo permite uma leitura mais apurada da percepção dos associados sobre a cooperativa como um todo, uma vez que estão distribuídos em todas as regiões do Estado. A condição de Representante, de certa maneira, foi um ponto de corte, determinando o público dessa pesquisa. Nesse estudo os Representantes da Cresal são chamados também de associados.Os dois questionários foram disponibilizados na plataforma Google Formulários no dia dois de agosto e enviados por e-mail para 41 pessoas, que tiveram um período de 10 dias para o retorno de suas respostas.

\section{ANÁLISE DE RESULTADOS}

Os resultados apresentados a seguir estão divididos em duas partes. A primeira traz os resultados coletados junto à equipe da UCP e a segunda, junto aos gestores. 
4.1. Análise dos resultados da pesquisa feita aos integrantes da equipe da UCP.

Os participantes desta pesquisa são uma Administradora, uma Socióloga, um Economista, o Coordenador da Unidade de Cooperativismo de Porto Alegre e o Coordenador Estadual das Unidades de Cooperativismo UCPs; conhecem a Cresal há mais de seis anos e todos participaram da intervenção da UCP junto à Cresal.

Na questão que perguntava "quais as principais ações realizadas pela Unidade de Cooperativismo - UCP na assistência às cooperativas", os participantes responderam que se ocupam do planejamento, da gestão administrativa e contábil, da organização social, da educação cooperativista e acesso a mercados, das redes de cooperação e intercooperação, capacitação de gestores e associados e apoio às ações da gestão através da prestação de serviços de ATERs cooperativo.

Na questão "quais foram as principais ações realizadas pela Unidade de Cooperativismo - UCP na cooperativa Cresal", foram apontadas o planejamento, a educação financeira e cooperativista (EAD), a capacitação dos representantes, a formulação e reformulação dos produtos oferecidos pela Cresal, a reformulação do processo eleitoral da cooperativa, o planejamento operativo e apoio bem como a monitoria na execução das atividades planejadas.

Perguntados "quanto às dificuldades encontradas na estruturação da Cresal", os participantes não encontraram muitas dificuldades, sendo que, das opções apontadas, todas ficaram abaixo de $50 \%$ de apontamentos. Considerando-se que havia 13 possibilidades de escolha, foram observados dois apontamentos para as opções: dificuldades para tomar decisões; estrutura organizacional de recursos humanos insuficiente; e escassez de comunicação interna e troca de informações. As opções: insegurança quanto às normativas do Banco Central e sistema financeiro; pouca estrutura organizacional de tecnologia e informática; limitação na organização 
financeira e contábil da cooperativa; e compreensão da organização da cooperativa e os papéis de cada membro, receberam um apontamento cada. Além dessas que foram apontadas anteriormente, teve um apontamento sobre a baixa participação/associação de colegas dos municípios do interior na Cresal. Um dos participantes não encontrou dificuldades e justificou "A Cresal é uma cooperativa muito bem organizada".

Em relação aos pontos positivos encontrados na estruturação da Cresal houve apontamentos em todas as opções apresentadas, sendo uma com destaque, marcada por todos os participantes se referindo à Participação dos conselheiros nos assuntos da cooperativa; outras opções com 4 apontamentos foram: a organização da cooperativa nas questões financeiras e contábeis e a organização documental (manuais, arquivos, documentos); 3 apontamentos para as tomadas de decisão da gestão de forma participativa e o conhecimento da legislação relacionada a cooperativas e cooperativas de crédito; 2 apontamentos para a segurança da gestão quanto às normativas do Banco Central e sistema financeiro, a estrutura organizacional relacionada a área de Tecnologia da Informação, a estrutura organizacional de recursos humanos, a compreensão da organização da cooperativa e os papéis de cada membro e a existência de um plano de ação em andamento; a comunicação interna e troca de informações recebeu somente um voto. Observa-se que os participantes desse grupo tiveram uma percepção muito similar como equipe, sobre a cooperativa. Cada membro da equipe havia focado num assunto diferente na tomada de informações. No entanto, pode-se observar que as respostas não diferem muito.

Quando questionados sobre a aceitabilidade dos gestores e associados da Cresal com relação à Unidade de Cooperativismo - UCP, a resposta foi positiva por todos os participantes, como também afirmam que os gestores e associados foram receptivos, disponibilizando os documentos e os materiais necessários ao trabalho a 
ser realizado. A experiência com relação à assistência em uma cooperativa de crédito eles também afirmaram ter sido positiva.

Ao serem questionados sobre as principais dificuldades encontradas nessa intervenção, junto aos gestores e associados da Cresal, três dos participantes do grupo responderam não ter percebido dificuldades, justificando que foi uma iniciativa dos gestores a busca pela unidade de cooperativismo e dois participantes apontaram dificuldades. Desses, um observou que há dificuldade no desenvolvimento de educação cooperativa da Cresal devido à distância entre os associados, pois estes, segundo ele, "estão espalhados por todo o Estado, o que pode ser amenizado através do curso EAD". O outro disse que há dificuldade de entender o cooperativismo de crédito por ter uma legislação própria e regulamentada como instituição financeira, além do fato de os gestores não atuarem na cooperativa em tempo integral, bem como não serem profissionais na administração o que acentua essa dificuldade.

Perguntados se existem características positivas na postura e na ação dos gestores e associados da Cresal que facilitaram o desenvolvimento do trabalho pela equipe da UCP na intervenção para estruturação da cooperativa, todos os integrantes desse grupo responderam que sim e 3 deles citaram "a participação" como a principal característica. Outras características também foram citadas: "transparência e inovação", "compartilhamento de responsabilidades para desenvolver as ações planejadas" "agilidade na busca de resoluções de problemas e desenvolvimento de ações", "comprometimento no desenvolvimento das ações planejadas" "participação da direção da Cresal e conselhos nas ações assim como de associados durante as assembleias", "organização da cooperativa, conhecimento da legislação”, "a abertura e a confiança para que os colegas pudessem se apropriar da situação e propor soluções. 'Fomos muito bem recebidos pelos gestores, colegas e funcionários."' (Participante 3). 
4.2. Análise dos resultados da pesquisa feita aos integrantes do grupo de gestores e associados da Cresal

O questionário elaborado aos gestores e associados da Cresal foi encaminhado para 36 participantes. A aplicação dos questionários ocorreu entre os dias 02 e 14 de agosto de 2019, tendo retornado 25 respostas. Todos os que responderam conhecem a cooperativa há mais de seis anos, sendo que quatro deles, desde que ela foi fundada. 10 estão envolvidos com a gestão há mais de seis anos, 10 até três anos, e 5 entre três e seis anos.

Sobre a área de atuação na Cresal, $48 \%$ dos que responderam fazem parte do grupo de representantes da Cresal no interior, uma pessoa participou somente como associada, uma já foi da diretoria e uma já foi representante, formando o Grupo 2 do grupo dos Gestores (vide 3.3 Público alvo da pesquisa). Os demais estão distribuídos entre Conselho de Administração - 3 pessoas, Conselho Fiscal - 2 pessoas, os membros da Diretoria - 3 pessoas, uma como ex-conselheira suplente e outra como contadora, completando o Grupo 1 (vide 3.3 Público alvo da pesquisa).

Quando perguntados "de que forma acontece a sua atuação na cooperativa", 23 dos 25 que responderam o questionário, disseram que divulgam a cooperativa para outras pessoas; 12 incentivam a participação dos cooperados nas questões da cooperativa; a mesma quantidade promove e incentiva a educação cooperativa; 8 participam das reuniões; 6 ajudam nas tomadas de decisão; o mesmo número de participantes disseram que ajudam na organização documental (revisão/construção de manuais); 4 auxiliam no aumento do portfólio dos produtos ou novas modalidades dos produtos; 3 ajudam na organização financeira da cooperativa; 1 pessoa atua no Conselho Fiscal; uma pessoa atua exclusivamente nos registros contábeis e informações BACEN - Banco Central do Brasil; e uma pessoa diz que sempre que possível busca participar das atividades da cooperativa. 
Dentre essas respostas, observou-se que do Grupo 1, os membros da Diretoria e do Conselho de Administração atuam em quase todos os campos apresentados; os membros do Conselho Fiscal apresentam três respostas que coincidem que são a participação nas reuniões, incentivo à participação dos cooperados nas questões da cooperativa e divulgam a cooperativa para outras pessoas. Já o grupo 2 atua mais nas ações de divulgação da cooperativa, incentivo dos cooperados à participação e promovem e incentivam a educação cooperativa, que são os campos com uma porcentagem maior de respostas. Observa-se nesse resultado que as opções estão mais relacionadas com a atuação administrativa, o que mostra que o resultado está de acordo com as funções dos participantes.

Ao serem perguntados sobre dificuldades da gestão da Cresal antes da intervenção da UCP, 60\% dos que responderam percebiam dificuldades. Dos que não percebiam haver dificuldades, a maioria está no Grupo 2. No entanto, este grupo mostra equilíbrio entre os que percebiam dificuldades e os que entendiam não haver dificuldades. Do Grupo 1, a maioria respondeu que percebia dificuldades; três responderam que não percebiam, dentre estes, dois atuam na gestão há menos de três anos (atuação posterior ao período em que ocorreu a intervenção), e dois manifestaram desacordo ou dificuldades em responder por conta da palavra “intervenção".

A respeito das principais dificuldades vivenciadas na gestão da Cresal antes da intervenção da Unidade de Cooperativismo - UCP, os gestores apontaram muitas dificuldades. A que mais se destaca é a comunicação interna e troca de informações,apontada por 10 participantes. Outras que tiveram destaque com 7 apontamentos cada, foram: a insegurança quanto às normativas do Banco Central e sistema financeiro e; pouca estrutura organizacional de tecnologia e informática e comunicação. Nota-se que a comunicação é o principal apontamento em quase todas as questões. 
Destaca-se também as dificuldades com a compreensão da organização da cooperativa e os papéis de cada membro bem como o desconhecimento da legislação cooperativa e cooperativas de crédito, ambas com 5 apontamentos cada. A pouca participação dos conselhos nos assuntos da cooperativa e a estrutura organizacional de recursos humanos insuficiente tiveram 4 apontamentos, assim como os que manifestaram não conhecer direito a Cresal; a limitação na organização financeira e contábil da cooperativa, obteve 3 apontamentos, as dificuldades para tomar decisões e a pouca organização documental (manuais, arquivos, documentos) tiveram 2 apontamentos cada. Foram também apontadas dificuldades como o planejamento, divulgação da Cresal, de seus produtos, de suas potencialidades.

Nessa questão os participantes do Grupo 1 apontaram a comunicação interna e troca de informações como a maior dificuldade recebendo 5 apontamentos; seguida do desconhecimento da legislação cooperativa e cooperativas de crédito e insegurança quanto às normativas do Banco Central e sistema financeiro com 4; a estrutura organizacional de recursos humanos insuficiente recebeu 3 apontamentos; a limitação na organização financeira e contábil da cooperativa, a pouca organização documental (manuais, arquivos, documentos) e a compreensão da organização da cooperativa e os papéis de cada membro, cada uma recebeu 2 apontamentos. As dificuldades para tomar decisões e a pouca participação dos conselhos nos assuntos da cooperativa receberam cada uma, um apontamento de participante do Grupo 1. As respostas foram emitidas por participante que não atuava junto à gestão.

Nota-se que a percepção dos gestores difere bastante da percepção dos membros da equipe da UCP. Tendo por base o diagnóstico elaborado pela equipe da UCP, pode-se supor que os membros da UCP detectaram as reais dificuldades da cooperativa, enquanto as respostas dos gestores supõe supõem um conhecimento empírico, um conhecimento individual ou parcial da realidade da cooperativa, como apontam Schneider, Hendges e Silva (2010), quando falam que as pessoas 
desconhecem o cooperativismo e que, nem mesmo os próprios associados têm conhecimentos suficientes para conceituar o que seria uma cooperativa. É importante conhecer as atividades e o papel de cada membro para que o gestor tenha uma confiança maior da sua cooperativa.

Com relação à Unidade de Cooperativismo - UCP e sua intervenção na Cresal, foi perguntado se sabiam o que faz uma Unidade de Cooperativismo - UCP, apenas um participante apontou total desconhecimento. Dos demais, 20 disseram saber o que a UCP faz e 4 participantes, manifestaram conhecer em parte. Perguntados se souberam da intervenção da UCP na Cresal, 18 responderam que sim, e 7 participantes disseram que não. Perguntados se participaram ativamente das ações desenvolvidas conjuntamente com a Unidade de Cooperativismo - UCP e a Cresal, a grande maioria respondeu que não participou ou participou em parte, e apenas 5 das pessoas que responderam o questionário participaram ativamente das ações. Olhando de forma mais aprofundada, percebe-se que os integrantes do Grupo 2 participaram em parte ou não tiveram nenhuma participação direta. Já do Grupo 1, as cinco pessoas que participaram mais ativamente são os Diretores e Conselheiros de Administração que atuam na gestão há mais de 3 anos, período em que ocorreu a atuação da UCP.

Sobre as pessoas que não souberam da intervenção da UCP na Cresal, duas delas manifestaram não ter compreendido o termo "intervenção", uma pessoa tem menos de 3 anos na gestão e as outras são do grupo 2 .

Com relação ao curso de educação cooperativa, promovido pela UCP juntamente com a Cresal, 23 dos participantes tinham conhecimento do curso, mas somente 8 participaram e concluíram o curso em ao menos uma das edições e duas pessoas não tiveram conhecimento. Perguntados se perceberam alguma modificação na gestão da Cresal a partir da intervenção da Unidade de Cooperativismo - UCP, 19 
responderam que sim e 6 participantes responderam que não perceberam nenhuma modificação.

No que diz respeito às mudanças percebidas, a questão que mais teve apontamentos (15), foi a divulgação da cooperativa junto aos cooperados e cooperados em potencial, seguida da comunicação entre cooperativa e cooperados com 14 apontamentos. Outras que também se destacaram na percepção dos participantes foram a atuação da gestão na cooperativa, com 9; com 6, o compromisso dos conselheiros com a gestão seguida da participação dos cooperados na Cresal com 5; a estruturação dos documentos organizacionais da cooperativa obteve 4 e as atividades administrativas internas da cooperativa, obteve 3. Cinco participantes apontaram que não perceberam nenhuma mudança.

Nessa questão é possível perceber novamente a comunicação e a divulgação sendo apontadas por um grande número de participantes. No entanto, essa percepção é significativamente maior nos participantes do Grupo 1, sendo apontada por 9 dos 10 participantes desse grupo, enquanto os participantes do Grupo 2, somente 6 dos 15 apontaram que houve uma mudança na divulgação da cooperativa. Já em relação à comunicação entre a cooperativa e cooperados, a percepção dos participantes do Grupo 2, aumentou para 7. Foi destaque também no Grupo 1 as opções: a atuação da gestão na cooperativa e o compromisso dos conselheiros com a gestão, sendo que ambas tiveram 5 apontamentos cada, e a estruturação dos documentos organizacionais da cooperativa foi apontada por 3 integrantes desse grupo.

Uma constatação na análise dos dados é que o sentimento de mudanças predominou entre os integrantes do Grupo 1 em praticamente todas as opções de respostas recebidas. A percepção do Grupo 2 só foi maior na opção sobre a participação dos cooperados na Cresal, com 3 dos cinco apontamentos. Porém, se for levado em consideração que o Grupo 2 tem mais participantes, a maior percepção de 
mudança continua sendo do Grupo 1. Aqui se confirma o que dizem Freitas, Freitas e Pedra (2011) sobre a importância da participação para a qualidade das tomadas de decisão.

Quando perguntados sobre como havia percebido a atuação da equipe da Unidade de Cooperativismo - UCP na Cresal, 16 respostas apontaram que a UCP propiciou a Educação Cooperativa; 10 pessoas selecionaram que a mesma ajudou no desenvolvimento das ações planejadas da cooperativa; 9 apontaram que a UCP Fez uma reorganização do plano de ação existente e priorizou ações, e 7 pessoas afirmaram que a UCP instigou a participação dos Conselheiros e Representantes nas ações da Cresal. A construção de um novo plano (diferente do que já existia) bem como a orientação e acompanhamento da execução de cada ação, receberam 4 apontamentos cada; a observação da atuação dos gestores sem maior envolvimento nas decisões, recebeu três apontamentos. Foi acrescido um apontamento "a distância da sede da cooperativa que dificulta o acompanhamento e maior conhecimento sobre o assunto". A opção: "não acompanhei essa atuação" foi apontada por seis participantes do Grupo 2 e um do Grupo 1. O participante do Grupo 1 que fez esse apontamento tem menos de 3 anos na Cresal.

Adotando o mesmo procedimento nas questões anteriores, considerou-se importante saber quem é o público que fez esses apontamentos. Dos 16 apontamentos que se referia a educação cooperativa, 8 deles foram do Grupo 1 e 8 do Grupo 2. Com relação à ajuda dispensada pela UCP no desenvolvimento das ações planejadas da cooperativa, dos 10 apontamentos, 8 foram feitos pelo Grupo 1; a reorganização do plano de ação existente que priorizou ações, dos 9 apontamentos, 6 foram feitos pelo Grupo 1; Já a opção que instigou a participação dos conselheiros e representantes nas ações da Cresal, recebeu 5 apontamentos do Grupo 1; Com relação a construção de um novo plano (diferente do que já existia) e a orientação e acompanhamento na execução de cada ação, receberam ambas 3 apontamentos cada desse grupo. Percebe-se novamente que a atuação da UCP foi mais bem 
percebida entre os participantes que estão mais próximos da cooperativa. Pode-se dizer, com isso, que as ações desenvolvidas estavam mais voltadas para a gestão e organização interna, ou então a divulgação das ações da cooperativa, ainda que tenha ocorrido, precisa ser mais bem trabalhada. De acordo com Seger, Eckhardt e Gessi, (2016), exige-se dos gestores muita criatividade para que a comunicação chegue ao receptor e este a compreenda de forma correta.

Perguntados sobre o período em que ocorreu a intervenção da Unidade de Cooperativismo - UCP na cooperativa, como havia sido sua experiência com relação à sua atuação na Cresal, 17 entenderam ter sido positiva e 8 apontaram indiferença. Sobre como foi a sua experiência com relação aos colegas 19 entenderam como positiva e 6 apontaram indiferença. Em relação à questão como foi a sua experiência com relação aos profissionais da Unidade de Cooperativismo - UCP 16 responderam ser positiva e 9 apontaram indiferença.

Quando questionados sobre como foi a sua experiência com relação às mudanças ocorridas, 18 responderam ter sido positiva, enquanto 7 apontaram indiferença; com relação a sua experiência na internalização dos princípios teóricos e práticos do cooperativismo 19 responderam ter sido positiva e 6 apontaram indiferença; sobre como foi a experiência em relação à sua postura e compromisso com a Cresal, 22 apontaram ter sido positiva, enquanto - 3 apontaram indiferença; e apenas 3 apontaram que a cooperativa mudou após a intervenção, 4 não acreditaram em mudanças significativas e 18 apontaram que as mudanças ocorreram em parte.

Essa última questão mostra que a maioria dos participantes tem uma visão formada sobre a Cresal a qual não mudou a partir da intervenção da UCP, mas sim, foram percebidas melhorias importantes como diz esse apontamento: "Minha visão sobre a cooperativa não mudou, no entanto penso que a atualização dos profissionais e conselheiros que trabalham diretamente na cooperativa e dos 
associados é de suma importância e, a UCP, certamente, reúne todas as condições de orientar estas atualizações."

Como essas outras respostas apontam percepções importantes sobre o que mudou em relação à cooperativa após a intervenção da Unidade de Cooperativismo UCP. As que foram mais perceptíveis pelos participantes se referem à comunicação entre a cooperativa e os cooperados e a divulgação da Cresal que tiveram quatro e três apontamentos respectivamente. Teve um destaque também à organização da Cresal como um todo, especialmente a financeira e documental, assim como a educação cooperativa, abordando os princípios e práticas do cooperativismo. Destaque também para a importância da parceria, do trabalho em conjunto buscando promover a Cresal. Dentre os apontamentos, temos "essa iniciativa foi percebida como uma busca da gestão em fazer esse contato mais aproximado", "muita vontade dos gestores da Cresal em se aproximar dos cooperados". Outras percepções também apresentaram o apoio à gestão, o atendimento e a agilidade na operacionalização de empréstimos. A importância de realizar um bom planejamento também foi apontada, bem como o profissionalismo da Cresal e a credibilidade. Merece destaque também a percepção de agente do interior, sobre a ação da UCP que "propiciou que a Cresal e seus dirigentes tivessem uma maior visão do processo cooperativo e organização interna".

Constata-se, portanto, que a grande parte dos depoimentos dos gestores em relação às ações da UCP aponta uma percepção positiva dessa intervenção. Considerando que o trabalho da UCP em conjunto com a Cresal foi uma iniciativa da própria cooperativa em promover ações que aproximassem a cooperativa dos cooperados, esse resultado vem ao encontro das afirmações de Freitas, Freitas e Pedra (ano), que apontam para a necessidade de haver um envolvimento e estímulo à participação social e que seja desenvolvido pela cooperativa, pois a iniciativa natural, nem sempre ocorre. 
Vale destacar que há considerações. Em três respostas foi apontada a necessidade de comunicação com os associados e com os conselhos. Necessidade de um maior envolvimento entre sócios, conselheiros e colaboradores, assim como a necessidade de melhorias na comunicação interna da cooperativa.

Houve considerações dos representantes da Cresal no interior que apontaram dificuldade de percepção da atuação da UCP na Cresal devido à distância. "Essa mudança é percebida pelos associados que estão mais próximos e participam com mais assiduidade das atividades/ações da cooperativa". Outra pessoa do interior disse que "recebem mais informações da cooperativa no interior, mas ainda poucos colegas conhecem os benefícios de participar da cooperativa". Essa constatação é percebida também pela equipe da UCP quando dizem da dificuldade da participação dos cooperados, pois estes "estão espalhados por todo o Estado". De certa maneira, o recebimento de informações já atenua o problema de comunicação, cuja importância Schmitz (2003) evidencia.

Um depoimento importante sobre o trabalho das UCPs e o cooperativismo veio de um participante do interior, que menciona o conhecimento desses agentes e o esforço constante para trabalhar o cooperativismo: "as pessoas que fazem parte do cooperativismo dentro da Instituição tem muito a contribuir e que faltam oportunidades para divulgar esse trabalho. A importância da inovação na forma de gestão. E que, estar preparado e preparar pessoas para trabalhar em prol da Cooperativa e cooperativismo é um desafio constante". Esse resultado vem ao encontro do que diz Schmitz (2003) sobre a importância de as cooperativas adotarem uma política de comunicação para divulgar a organização cooperativa aos cooperados e à sociedade em geral.

Outro destaque importante se refere aos encontros e cursos que foram desenvolvidos em conjunto para os Representantes da Cresal no interior: "a importância da participação e divulgação da cooperativa, capacitação proporcionada 
pelos encontros e curso" e vê a necessidade de manter este trabalho. Essa constatação feita por participante dos Representantes da Cresal se confirma no que dizem Schneider, Hendges e Silva (2010) quando falam da formação como uma possibilidade de aperfeiçoamento das capacidades individuais das pessoas, podemos entender que a cooperativa propiciou essa capacitação aos cooperados Representantes para que estes pudessem desempenhar as funções de divulgação da Cresal no interior.

\section{CONCLUSÃO}

A partir da pesquisa realizada no presente estudo, por meio de aplicação de dois questionários, um para a equipe da UCP que realizou um trabalho de melhorias na gestão da Cresal e outro para os gestores e associados que participaram de alguma maneira nessa intervenção, foi analisado como estes compreenderam as ações realizadas na Cresal pela UCP. Para isso, com base no histórico do estudo de caso e as respostas colhidas dos participantes da equipe da UCP, foi possível diagnosticar o quanto os gestores e associados perceberam a atuação da UCP. Ao mesmo tempo foram analisadas as respostas do grupo de gestores que estiveram mais próximos do evento e os associados, Representantes da Cresal, que estiveram mais distantes do processo em si, fazendo um comparativo entre estes dois grupos.

Constatou-se que os gestores apontaram mais ações realizadas em comparação ao grupo de Representantes. Os gestores que participaram do processo transparecem melhor percepção das ações realizadas, inclusive a melhoria na comunicação entre cooperativa e cooperados e a divulgação da cooperativa junto aos cooperados e cooperados em potencial. Curiosamente estas ações não tiveram destaque expressivo junto aos associados - Representantes da Cresal, que estiveram distantes do processo. Se for considerado que os Representantes são associados com maior oportunidade de acesso a informações, pode-se supor que as ações da 
cooperativa junto aos demais associados que estão no interior do Estado são ainda menos percebidas.

Diante disso pergunta-se: será que a comunicação e a divulgação feita pela Cresal contemplaram os anseios dos cooperados que estão distribuídos por todo o estado? Será que a forma utilizada foi adequada para que os cooperados tivessem percebido uma mudança na comunicação nesse período estudado? Será que o fato de a ação "informação e comunicação cooperativa" não ter demonstrado a eficácia desejada pelos gestores da Cresal é uma realidade que ocorre apenas nesta cooperativa? Em um tempo onde a comunicação é fundamental para atingir os objetivos das organizações, ela precisa ser utilizada de maneira em que o interlocutor tenha a compreensão fiel da informação repassada. Conforme Seger, Eckhardt e Gessi (2016), para alcançar excelência dos produtos e serviços, as organizações terão que perceber que a eficácia da comunicação é de fundamental importância. Somente quando o interlocutor tem a informação correta, as atividades serão realizadas de acordo com o que propõe a organização.

Ainda assim, o resultado do estudo apontou que essa intervenção foi positiva, trazendo a Educação Cooperativa, a Capacitação, a Comunicação e a Divulgação informações sobre a cooperativa e o cooperativismo - como destaque entre as ações desenvolvidas.

De parte dos resultados alcançados, entende-se que esse estudo não se esgota aqui. Sugere-se um aprofundamento maior sobre esse tema de como ocorre o processo de comunicação entre cooperativas, cooperados e sociedade no que se refere ao recebimento e a compreensão das informações repassadas. Sugere-se, também, um estudo sobre a quantidade/qualidade de informações e a eficácia destas com relação aos resultados alcançados das organizações cooperativas. 
À Cresal sugere-se uma capacitação mais aprofundada dos seus Representantes sobre cooperativismo, com foco na Educação Cooperativa e a Cresal, suas ações e filosofia, além dos valores e princípios cooperativos. Essa capacitação qualifica melhor o representante ao desempenho das suas funções de ser um elo de comunicação entre a cooperativa e cooperados, e divulgar o cooperativismo e a Cresal junto aos cooperados e cooperados em potencial na sua região. Sugere-se, da mesma forma, uma análise quantitativa dos resultados da cooperativa, abrangendo um período maior e comparando o antes e o depois, para saber em números quais os resultados obtidos após esse período.

\section{REFERÊNCIAS}

CRESAL (site). História. 2019. Disponível em: http://www.cresal.coop.br/novosite/historia-linha-do-tempo/ Acesso em: 29 ago. 2019.

DECRETO No 49.333, DE 04 DE JULHO 2012. Institui o Programa de Extensão Cooperativa - PEC - RS e o Programa de Acompanhamento à Gestão - PAG - RS, no âmbito da Política Estadual de Fomento à Economia da Cooperação e do Programa de Cooperativismo do Estado do Rio Grande do Sul, e dá outras providências. Disponível em: https://www.legisweb.com.br/legislacao/?id=243047. Acesso em: 08 jul. 2019.

FREITAS, Alair Ferreira; FREITAS, Alan Ferreira; PEDRA, Michelle de Sá. Participação na gestão de cooperativas: A estratégia de organização do quadro social (OQS). Em Extensão, Uberlândia, v.10, n. 1, p. 90-99, jan/jun. 2011. Disponível em: http://www.seer.ufu.br/index.php/revextensao/article/view/20648. Acesso em: 08 abr. 2019.

GIL, Antônio Carlos. Como elaborar projetos de pesquisa - $4^{\mathrm{a}}$ Ed. 12 reimpressões Editora Atlas S.A. São Paulo, 2009. 
JORNAL DO COMÉRCIO. Cooperativismo impulsiona desenvolvimento do Rio Grande do Sul. Notícia da edição impressa de 12 de julho de 2019. Disponível em: https://www.jornaldocomercio.com/_conteudo/especiais/cooperativismo_2019/2019/ 06/690827-cooperativismo-impulsiona-desenvolvimento-do-rio-grande-do-sul.html. Acesso em: 15 nov. 2019.

LEI N. ${ }^{\circ} 13.839$ DE 5 DE DEZEMBRO DE 2011. Institui a Política Estadual de Fomento à Economia da Cooperação, cria o Programa de Cooperativismo e dá outras providências. Disponível em: https://www.legisweb.com.br/legislacao/?id=156099. Acesso em: 08 jul. 2019.

MELO, Diego Fonseca de. 2013. O papel da Extensão Rural e do Cooperativismo na inserção do uso de ferramentas de gestão e desenvolvimento de produtores rurais familiares: O caso da Cooperativa Multiflor. Universidade de Brasília UnB. Disponível em: $\quad$ http://bdm.unb.br/bitstream/10483/4605/1/2013_DiegoFonsecadeMelo.pdf. Acesso em: 22 ago. 2019.

PEIXOTO, Marcus. Extensão Rural no Brasil: Uma Abordagem Histórica da Legislação, 2008. Disponível em: https://www12.senado.leg.br/publicacoes/estudoslegislativos/tipos-de-estudos/textos-para-discussao/td-48-extensao-rural-no-brasiluma-abordagem-historica-da-legislacao. Acesso em: 22 ago. 2019.

SCHMITZ, Vera Regina. Comunicação nas cooperativas: seus diferentes públicos e instrumentos. In SCHNEIDER, Odelso José. Educação Cooperativa e suas práticas, p. 195. Ed. Unisinos, 2003.

SCHNEIDER, Odelso José; HENDGES, Margot e SILVA; Antonio Cesar Machado da. Educação e Capacitação Cooperativa: os desafios no seu desempenho. Ed. Unisinos, 2010. 
SEGER, Flávia Aline; ECKHARDT, Francieli Teresinha; GESSI, Nedisson Luis. A importância da comunicação nas organizações, 2016. Disponível em: http://www.fema.com.br/sitenovo/wp-content/uploads/2016/09/2-A-Importância-daComunicação-nas-Organizações.pdf. Acesso em: 24 out.2019.

TEJERA, Marta. Emater investe no cooperativismo ao formar grupo para assessorar o setor. Gov.RS, 2011. Disponível em: https://estado.rs.gov.br/emater-investe-nocooperativismo-ao-formar-grupo-para-assessorar-o-setor. Acesso em: 29 ago. 2019. 
